\title{
Menstrual factors, reproductive history, and risk of lung cancer: a multi-center population-based cohort study in Chinese females
}

\author{
Zhuoyu Yang ${ }^{1 \#}$, Fei Wang ${ }^{1 \#}$, Fengwei Tan ${ }^{2 \#}$, Wei Cao ${ }^{1}$, Yongjie $\mathrm{Xu}^{1}$, Chao Qin ${ }^{1}$, Yiwen Yu ${ }^{1}$, Liang Zhao ${ }^{1}$, \\ Yan Wen ${ }^{1}$, Zheng $\mathrm{Wu}^{1}$, Yadi Zheng ${ }^{1}$, Yunyong Liu ${ }^{3,4}$, Lianzheng $\mathrm{Yu}^{5}$, Donghua $\mathrm{Wei}^{6}$, Dong Dong ${ }^{7}$, \\ $\mathrm{Ji} \mathrm{Cao}^{8}$, Shaokai Zhang', Shipeng Yan ${ }^{10}$, Ning Wang ${ }^{11}$, Xianzhen Liao ${ }^{10}$, Lingbin Du ${ }^{12}$, Jiang Li ${ }^{1}, \mathrm{Ni} \mathrm{Li}^{1,13,14}$, \\ Wanqing Chen ${ }^{1}$, Jie $\mathrm{He}^{2}$
}

${ }^{1}$ Office of Cancer Screening, National Cancer Center/National Clinical Research Center for Cancer/Cancer Hospital, Chinese Academy of Medical Sciences and Peking Union Medical College, Beijing, China; ${ }^{2}$ Department of Thoracic Surgery, National Cancer Center/National Clinical Research Center for Cancer/Cancer Hospital, Chinese Academy of Medical Sciences and Peking Union Medical College, Beijing, China; ${ }^{3}$ Department for Cancer Prevention and Treatment of Liaoning Province/Cancer Hospital of China Medical University, Liaoning Cancer Hospital \& Institute, Shenyang, China; ${ }^{4}$ Division of Pneumoconiosis School of Public Health, China Medical University, Shenyang, China; ${ }^{5}$ Department of Noncommunicable Chronic Disease Prevention, Liaoning Center for Disease Control and Prevention, Shenyang, China; ${ }^{6}$ Cancer Department of Physical Examination, Anhui Provincial Cancer Hospital, Hefei, China; ${ }^{7}$ Office of Cancer Prevention and Treatment, Xuzhou Cancer Hospital, Xuzhou, China; ${ }^{8}$ Department of Experimental Pathology, Tumor Hospital of Guangxi Medical University, Nanning, China; ${ }^{9}$ Department of Cancer Epidemiology, Affiliated Cancer Hospital of Zhengzhou University/Henan Cancer Hospital, Henan Engineering Research Center of Cancer Prevention and Control, Henan International Joint Laboratory of Cancer Prevention, Zhengzhou, China; ${ }^{10}$ Department of Cancer Prevention and Control, Hunan Cancer Hospital \& The Affiliated Cancer Hospital of Xiangya School of Medicine, Central South University, Changsha, China; ${ }^{11}$ Key Laboratory of Carcinogenesis and Translational Research (Ministry of Education/Beijing), Beijing Office for Cancer Prevention and Control, Peking University Cancer Hospital \& Institute, Beijing, China; ${ }^{12}$ Department of Cancer Prevention, The Cancer Hospital of the University of Chinese Academy of Sciences (Zhejiang Cancer Hospital)/IBMC, Chinese Academy of Sciences, Hangzhou, China; ${ }^{13}$ Chinese Academy of Medical Sciences Key Laboratory for National Cancer Big Data Analysis and Implement, Beijing, China; ${ }^{14}$ Jiangsu Key Lab of Cancer Biomarkers, Prevention and Treatment, Jiangsu Collaborative Innovation Center for Cancer Personalized Medicine, Nanjing Medical University, Nanjing, China

Contributions: (I) Conception and design: J He, N Li; (II) Administrative support: W Chen, F Tan, J Li; (III) Provision of study materials or patients: L Du, X Liao, N Wang, S Yan, S Zhang, J Cao, D Dong, D Wei, L Yu, Y Liu; (IV) Collection and assembly of data: Z Yang, F Wang, F Tan, C Qin, W Cao, Y Xu, Y Yu, L Zhao, Z Wu, Y Wen, Y Zheng; (V) Data analysis and interpretation: Z Yang, F Wang, F Tan; (VI) Manuscript writing: All authors; (VII) Final approval of manuscript: All authors.

\#These authors contributed equally to this work.

Correspondence to: Ni Li, PhD. Office of Cancer Screening, National Cancer Center/National Clinical Research Center for Cancer/Cancer Hospital, Chinese Academy of Medical Sciences and Peking Union Medical College, No. 17 Panjiayuannanli, Chaoyang District, Beijing 100021, China. Email: nli@cicams.ac.cn; Jie He, MD, PhD. Department of Thoracic Surgery, National Cancer Center/National Clinical Research Center for Cancer/Cancer Hospital, Chinese Academy of Medical Sciences and Peking Union Medical College, No. 17 Panjiayuannanli, Chaoyang District, Beijing 100021, China. Email: prof.jiehe@gmail.com.

Background: Female menstrual and reproductive factors, as remarkable indicators of hormone effect, were hypothesized to be associated with lung cancer risk, whereas the existed epidemiological evidence was inconsistent. Our study aims to investigate the association between menstrual and reproductive factors and lung cancer risk based on the Chinese Lung Cancer Screening Program.

Methods: This study was based on a large-scale multi-center population cohort across China recruiting individuals aged 40-74 years old between 2013-2018. Cox regression model was applied to estimate the HRs and $95 \%$ CIs. Restricted cubic spline (RCS) analysis was used to estimate dose-response relationships and test for nonlinear associations.

Results: Among 553,434 female participants, 1,529 incident lung cancer cases were identified with a median follow-up of 3.61 years. With adjustment for multiple covariates and all significant hormonal factors, elevated lung cancer risk was associated with later age (15, or $\geq 16$ years) at menarche (HR =1.27, $95 \%$ CI: 
1.04-1.56; HR =1.45, 95\% CI: 1.19-1.76), later age (25-29, or $\geq 30$ years) at first live birth (HR =1.27, 95\% CI: $1.13-1.43$; HR $=1.23,95 \%$ CI: $1.00-1.51$ ), and benign breast disease history (HR =1.25, 95\% CI: 1.10 1.41). For postmenopausal females specifically, surgical menopause (HR =1.62; 95\% CI: 1.29-2.05) and other surgeries on the reproductive system ( $\mathrm{HR}=1.19 ; 95 \% \mathrm{CI}$ : 1.01-1.40) both appeared to be predictive of elevated lung cancer risk. Concerning age at menopause, a nonlinear association was observed (P-nonlinear $=0.0126$ ). Increased lung cancer risk was observed among females with age at menopause especially above 50. Although we observed no significant associations between longer time ( $\geq 13$ months) of breastfeeding and lung cancer risk among all participants (HR =0.86; 95\% CI: 0.71-1.04), significant decreased adenocarcinoma risk ( $\mathrm{HR}=0.65$; 95\% CI: 0.53-0.81) was noted among nonsmoking females.

Conclusions: Our findings add some support for the role of menstrual and reproductive factors in lung carcinogenesis. However, these relationships were complex, and required further investigations addressing the biological mechanisms.

Keywords: Lung cancer; hormones; population-based; cohort study.

Submitted Jul 07, 2021. Accepted for publication Sep 16, 2021.

doi: $10.21037 /$ tlcr-21-552

View this article at: https://dx.doi.org/10.21037/tlcr-21-552

\section{Introduction}

Lung cancer remains the leading cause of cancer deaths worldwide. In 2020, more than one-third of lung cancer cases and deaths occurred in China (1). From 2000 to 2015, the female lung cancer incidence rate doubled in China $\left(57.26 / 10^{5}\right.$ vs. $\left.27.77 / 10^{5}\right)(2)$ with an average annual change percentage (AACP) of $4.5 \%$ (3).

Smoking is the leading risk factor for lung cancer and is linked to over $80 \%$ of lung cancers worldwide (4). In China, $75.04 \%$ of lung cancer deaths were attributable to tobacco smoking in males, whereas only $18.35 \%$ of lung cancer deaths in females were attributed to active smoking (5). There were still two-thirds of female lung cancer associated with unidentified risk factors besides active smoking, involuntary smoking, occupational agents, indoor radon and low fruit intake (5). Accumulating evidence suggests that female lung cancers differed from lung cancer in males concerning the clinical characteristic (6). Female lung cancers are mainly composed of adenocarcinoma (7) and have a higher frequency of epidermal growth factor receptor (EGFR) mutations compared with male lung cancer cases (8). These literatures suggested that gender differences in clinical characteristics may underlie the effect of hormone-related factors.

Experimental studies showed that steroid hormonerelated receptors including estrogen receptors are frequently expressed in lung cancer tissue (9). By binding to estrogen receptors $\alpha(\mathrm{ER} \alpha)$, estrogen may promote cell proliferation or decreasing apoptosis through activating target genes (10-13). Therefore, estrogen is postulated as an important agent in female cancer development (14).

Menstrual factors and reproductive history, which are remarkable indicators of endogenous hormonal effect, have been widely explored in epidemiological studies (15-33). However, inconsistent associations have been suggested (15-19,21,23,26,29,32). Therefore, we conducted a meta-analysis of worldwide studies on endogenous sex steroid hormone (34). Though overall results showed that higher levels of sex steroid hormones were associated with decreased female lung cancer risk, Asian studies revealed quite different associations concerning the age at menopause, age at first live birth, and reproductive window, compared with Western studies. For the Asian population, cohort studies in Japan, Singapore and China $(19,22,23)$ have reported significant associations with age at menarche and menopause, reproductive period, live birth history, and reproductive surgical history. However, multi-center cohort studies with the estimation of lung adenocarcinoma risk are lacking in Chinese females (25-27).

This study aims to investigate the association between reproductive factors and risk of lung cancer and specifically, risk of adenocarcinoma, among Chinese females in a multicenter population cohort. We present the following article in accordance with the STROBE reporting checklist (available at https://dx.doi.org/10.21037/tlcr-21-552). 


\section{Methods}

\section{Study design and population}

We conducted a multi-center prospective cohort study based on the Chinese lung cancer screening program, a non-profit program launched in 2012 and funded by the Ministry of Finance and the National Health Commission of China. Participants were eligible if they were asymptomatic of lung cancer, had no history of any cancer types, and aged between 40-74 years. Eligible participants who provided written informed consent were interviewed by trained staff to collect information about their exposure to risk factors. Then, their lung cancer risks were evaluated using an established risk score system. Individuals who were defined as high-risk for lung cancer were recommended to undergo a free LDCT examination at a tertiary-level hospital designated by the program.

Eight study provinces (Anhui, Beijing, Guangxi, Henan, Hunan, Jiangsu, Liaoning, and Zhejiang province) were selected for our study based on the following criteria: (I) complete cancer registration data, (II) complete vital statistics data, (III) cross-reference medical records from hospital information systems, and (IV) minor migration representing a relatively stable population. Between 2013-2018, there were 1,016,740 eligible participants recruited in the Chinese lung cancer screening program, among which 570,713 were females. Eventually, a total of 553,434 females with valid information concerning the age at menarche (8-18 years), menopause (30-60 years), and first live birth (18-45 years) were included in the study (Figure 1).

The study was conducted in accordance with the Declaration of Helsinki and approved by the Ethics Committee of China National Cancer Center/Cancer Hospital, Chinese Academy of Medical Sciences and Peking Union Medical College (number of IRB:15070/997). Informed consent was taken from all individual participants.

\section{Exposure assessment}

Potential lung cancer risk factors except for height and weight were collected by self-report questionnaire at baseline entry. Menstrual factors include age at menarche $(<13,13,14,15$, or $\geq 16$, years), menopause status of the postmenopausal females (natural menopause or surgical menopause, surgical menopause was defined as menopause caused by surgeries including hysterectomy and oophorectomy, natural menopause was defined as menopause caused by the natural aging process without surgical intervention), age at menopause $(<45,45-49$, $50-54$ or $\geq 55$, years) and reproductive period (time between menarche and menopause, $<30,30-34,35-39$ or $\geq 40$, years). The reproductive history contained age at first live birth (nulliparous, $<25,25-29$, or $\geq 30$, years), duration of breastfeeding ( $0,1-12$, or $\geq 13$, months), benign breast disease history (mainly including breast fibroma and cystic hyperplasia) and surgical history on the reproductive system (surgeries other than hysterectomy and oophorectomy, mainly including tubal ligation, cesarean section, and myomectomy of the uterus).

Eight provinces were classified as developed areas (Beijing, Zhejiang, and Jiangsu Provinces) or developing areas (Anhui, Hunan, Liaoning, Guangxi, and Henan Provinces) based on each province's per capita gross domestic product (GDP) values in 2018. Marital status was defined as married or other (including unmarried, divorced, or widowed). Education level was defined in three categories, low (less than elementary school), medium (junior or high school or equivalent), and high (college degree equivalent or higher). Height and weight measured wearing light clothes without shoes were used to calculate the body-mass index (BMI), which was divided into 4 categories according to the Chinese standard: underweight $\left(<18.5 \mathrm{~kg} / \mathrm{m}^{2}\right)$, normal $\left(18.5-23.9 \mathrm{~kg} / \mathrm{m}^{2}\right)$, overweight $(24.0-$ $\left.27.9 \mathrm{~kg} / \mathrm{m}^{2}\right)$ or obese $\left(\geq 28.0 \mathrm{~kg} / \mathrm{m}^{2}\right)$. Smoking status was classified as current ( $>1$ cigarette/day for at least 6 months), former (previously smoked and have quit for at least 6 months), and never-smokers (those who reported neither current smoking status nor smoking history). Exposures to environmental tobacco smoke (yes or no) referred to exposure to tobacco combustion products from smoking by indoor regular smokers ( $>1$ cigarette/day for at least 6 months) in both workplace and living place. Exposures to cooking smoke were categorized as 'none ( $0 \mathrm{~h} /$ day)', 'little (0-1 h/day)', 'some (1-4 h/day)', 'much ( $>4$ h/day)' by selfreport. Occupational exposures referred to the exposures to either one of asbestos, rubber, dust, pesticide, radiation, beryllium, uranium, and radon for at least one year. History of chronic respiratory disease (yes or no) referred to previous clinical diagnoses of pulmonary tuberculosis, chronic bronchitis, emphysema, asthmatic bronchiectasis, silicosis, and pneumoconiosis, etc. Family history of lung cancer (yes or no) referred to previous clinical diagnosis of 


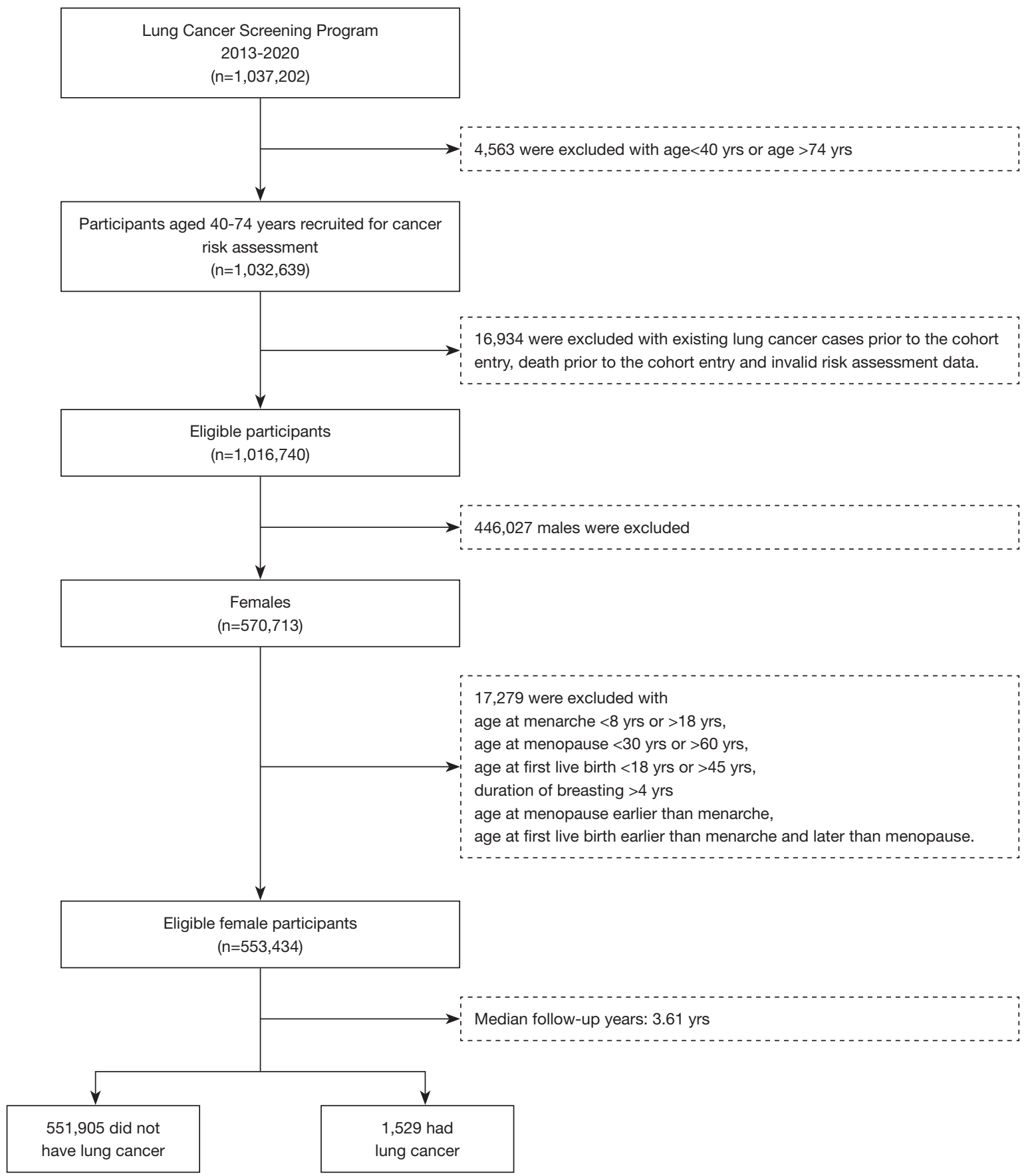

Figure 1 Workflow of the Chinese Lung Cancer Screening Program. yrs, years.

cancer among participants' first-degree relatives.

\section{Follow-up of participants}

Follow-up of each participant began when the baseline questionnaire was finished and ended at first diagnosis of lung cancer, death, last documented follow-up contact, or $20^{\text {th }}$ June 2020, whichever came first. We linked the system of our program to the cancer registry system and death surveillance system to obtain information on lung cancer incidence. The information was also cross-referenced with records from the medical insurance system and local 
hospitals. All cancer cases were classified according to the International Classification standards (ICD-10), in which lung cancer was coded as C34.

\section{Quality control}

A clinical expert committee consisting of thoracic surgeons, radiologists, and pathologists was formed to assure the accuracy of lung cancer diagnoses. Identified lung cancer cases, as well as their clinical stage and histological type, were cross-referenced with the cancer registration system, vital statistics data, health insurance system, and medical records. Overall, $94.0 \%$ of lung cancer cases were matched across databases. For the remaining cases with unsuccessful linkages, telephone interviews were further constructed to verify the information of lung cancer cases and deaths.

\section{Statistical analysis}

The baseline questionnaire data and information on lung cancer cases were used in the analysis. Continuous variables are presented as the mean \pm standard deviation (SD) and compared using $t$-tests. Categorical variables were described by proportions and compared using Chi-square tests.

The risk of developing lung cancer in relationship to baseline menstrual and reproductive factors was evaluated using Cox regression models. Each reproductive factor was modeled separately in relation to disease outcome. Notably, menopause status (natural or surgical menopause) and age at menopause were evaluated among postmenopausal females only. Estimation of hazard ratios (HRs) and 95\% confidence intervals (CIs) was conducted with adjustment of covariates including age at enrollment (continuous), education (low, medium, or high), BMI (underweight, normal, overweight or obese), smoking status (current, former or neversmoker), exposures to environmental tobacco smoke (yes or no), exposure to cooking smoke (none, little, some, or much), occupational exposures (yes or no), history of chronic respiratory disease (yes or no) and family history of lung cancer (yes or no). Considering the within-cluster correlation of different provinces, a shared frailty model was used, in which cluster effects of the province are incorporated into the model as independent and identically distributed variables.

For originally continuous variables, dose-response relationships and tests for non-linear associations were conducted using restricted cubic spline (RCS) regression with three knots (placed at the 5th, 50th, and 95th percentiles) (35). The median values were assigned as the spline referent.

Moreover, associations were further investigated in multivariable models among all recruited females and postmenopausal females only. The final multivariable models contain statistically significant risk factors including age at menarche, age at first live birth, duration of breastfeeding, benign breast disease, surgery on the reproductive system, menopause status and age at menopause (the last two for postmenopausal females only). Considering the low smoking prevalence of our participants, sensitivity analyses were further conducted among neversmokers.

Tests in this study were all two-sided and $\mathrm{P}<0.05$ was considered statistically significant. All statistical analyses were conducted using the SAS statistical software, version 9.4 (SAS Institute Inc, Cary, NC, USA).

\section{Results}

During a median follow-up of 3.61 years, 553,434 females were diagnosed with 1529 lung cancer, for an incidence density of $75.19 / 10^{5}$ person-years. (Figure 1). Baseline characteristics of the study population stratified by lung cancer status were presented in Table 1. The mean age of recruited participants was $55.76 \pm 8.64$ years, with $95.73 \%$ never-smokers and $37.70 \%$ passive smokers. Adenocarcinoma was the predominant histology type of lung cancer cases, accounting for $91.20 \%$.

Compared with the non-case group, lung cancer patients were older $(59.72 \pm 7.48$ vs. $55.75 \pm 8.64$ years $)$, and had a higher prevalence of passive smoking (41.14\% vs. 37.69\%), chronic respiratory diseases $(26.29 \%$ vs. $20.43 \%)$ and family history of lung cancer (17.72\% vs. 11.67\%). With respect to reproductive factors, lung cancer patients were at a later age of menarche $(14.63 \pm 1.67$ vs. $14.27 \pm 1.61$ years), first live birth $(25.23 \pm 4.66$ vs. $24.85 \pm 4.70$ years $)$ and menopause $(49.69 \pm 3.36$ vs. $49.41 \pm 3.17$ years), reported shorter time of breastfeeding (12.31 $\pm 7.98 v s .12 .46 \pm 8.68$ months), and had a higher proportion of benign breast disease history (35.32\% vs. $31.44 \%)$.

After adjustment for multiple covariates (detailed in "Statistical Analysis" and footnote of Table 2), the associations between reproductive factors and lung cancer risk overall, and adenocarcinoma specifically, were listed in Table 2. Increased lung cancer risk was associated with later age ( 15 , or $\geq 16$ years) at menarche (vs. 13 years: $\mathrm{HR}=1.26$, 95\% CI: $1.03-1.54$; HR $=1.43$, 95\% CI: $1.17-1.73$ ), later 
Table 1 Baseline characteristics of participants by lung cancer status

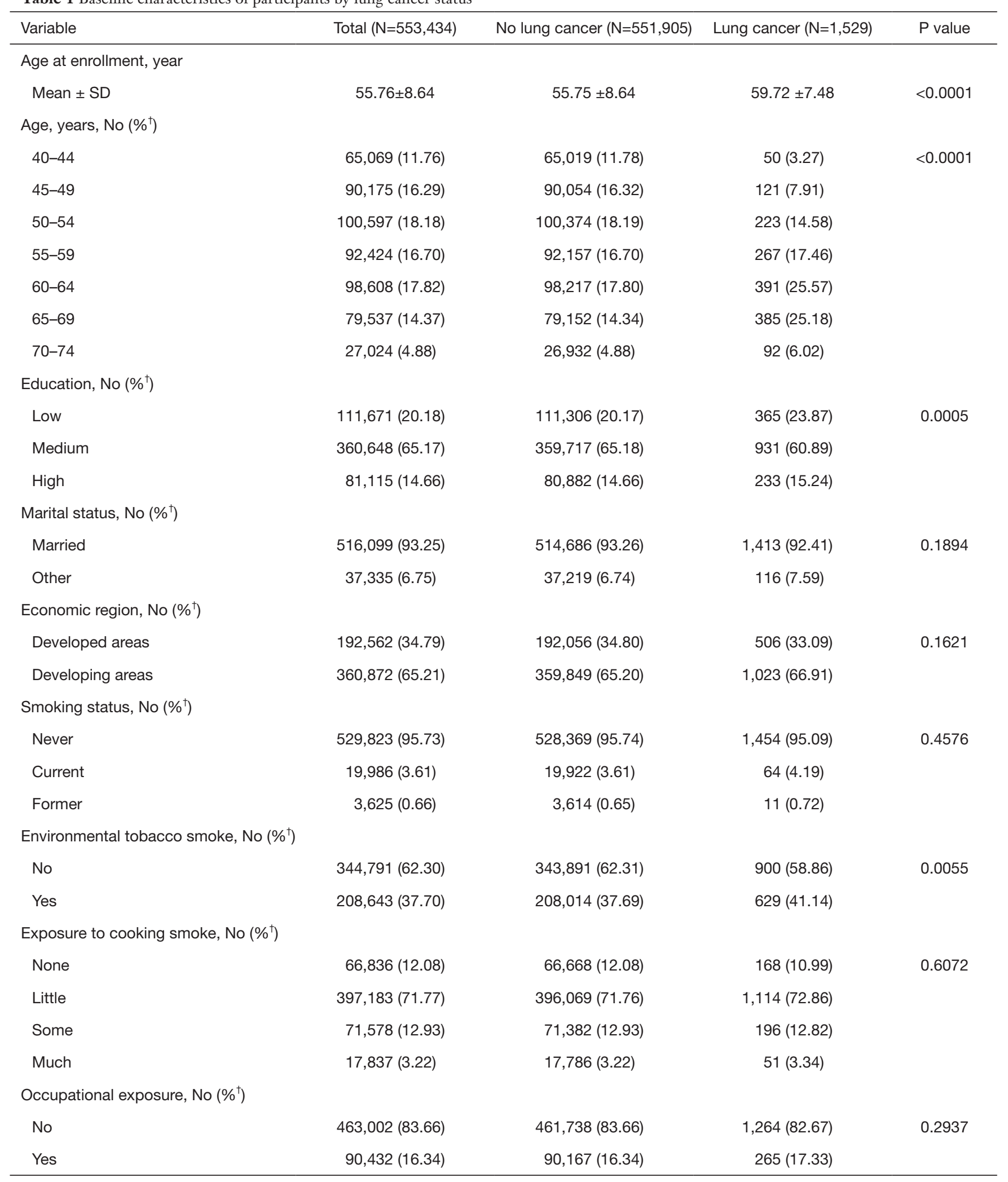

Table 1 (continued) 
Table 1 (continued)

\begin{tabular}{|c|c|c|c|c|}
\hline Variable & Total $(\mathrm{N}=553,434)$ & No lung cancer $(\mathrm{N}=551,905)$ & Lung cancer $(\mathrm{N}=1,529)$ & $P$ value \\
\hline Underweight & $12,083(2.18)$ & $12,047(2.18)$ & $36(2.35)$ & 0.7604 \\
\hline Normal & $303,311(54.81)$ & $302,490(54.81)$ & $821(53.70)$ & \\
\hline Overweight & 190,799 (34.48) & $190,266(34.47)$ & $533(34.86)$ & \\
\hline \multicolumn{5}{|c|}{ Family history of lung cancer, No $\left(\%^{\dagger}\right)$} \\
\hline No & 488,776 (88.32) & $487,518(88.33)$ & $1,258(82.28)$ & $<0.0001$ \\
\hline Yes & $64,658(11.68)$ & $64,387(11.67)$ & $271(17.72)$ & \\
\hline \multicolumn{5}{|c|}{ History of chronic respiratory diseases, No $\left(\%^{\dagger}\right)$} \\
\hline \multicolumn{5}{|l|}{ Age at menarche, year } \\
\hline Mean \pm SD & $14.27 \pm 1.61$ & $14.27 \pm 1.61$ & $14.63 \pm 1.67$ & $<0.0001$ \\
\hline$<13$ & $68,602(12.40)$ & $68,465(12.41)$ & $137(8.96)$ & $<0.0001$ \\
\hline 13 & 113,617 (20.53) & $113,348(20.54)$ & 269 (17.59) & \\
\hline 14 & $145,319(26.26)$ & $144,956(26.26)$ & $363(23.74)$ & \\
\hline 15 & 105,217 (19.01) & $104,906(19.01)$ & $311(20.34)$ & \\
\hline$\geq 16$ & $120,679(21.81)$ & $120,230(21.78)$ & $449(29.37)$ & \\
\hline \multicolumn{5}{|c|}{ Menopause status ${ }^{\ddagger}$, No $\left(\%^{\dagger}\right)$} \\
\hline $45-49$ & $126,294(34.62)$ & 125,909 (34.64) & $385(30.05)$ & \\
\hline $50-54$ & 200,368 (54.93) & 199,631 (54.92) & $737(57.53)$ & \\
\hline$\geq 55$ & $17,467(4.79)$ & $17,386(4.78)$ & $81(6.32)$ & \\
\hline \multicolumn{5}{|c|}{ Reproductive period ${ }^{\ddagger}$, year } \\
\hline Mean \pm SD & $34.98 \pm 3.50$ & $34.98 \pm 3.49$ & $34.98 \pm 3.61$ & 0.9929 \\
\hline$<30$ & 23,099 (6.33) & $23,007(6.33)$ & $92(7.18)$ & $<0.0001$ \\
\hline $30-34$ & 116,577 (31.96) & 116,175 (31.96) & $402(31.38)$ & \\
\hline $35-39$ & 199,028 (54.56) & $198,338(54.57)$ & $690(53.86)$ & \\
\hline$\geq 40$ & $26,061(7.14)$ & $25,964(7.14)$ & $97(7.57)$ & \\
\hline
\end{tabular}

Table 1 (continued) 
Table 1 (continued)

\begin{tabular}{|c|c|c|c|c|}
\hline Variable & Total $(\mathrm{N}=553,434)$ & No lung cancer $(\mathrm{N}=551,905)$ & Lung cancer $(\mathrm{N}=1,529)$ & $P$ value \\
\hline Mean \pm SD & $24.85 \pm 4.70$ & $24.85 \pm 4.70$ & $25.23 \pm 4.66$ & 0.0015 \\
\hline Nulliparous & $12,642(2.28)$ & $12,611(2.28)$ & $31(2.03)$ & $<0.0001$ \\
\hline$<25$ & $200,009(36.14)$ & $199,540(36.15)$ & $469(30.67)$ & \\
\hline$\geq 30$ & $37,214(6.72)$ & $37,086(6.72)$ & $128(8.37)$ & \\
\hline \multicolumn{5}{|c|}{ Duration of breastfeeding, month } \\
\hline Mean \pm SD & $12.46 \pm 8.68$ & $12.46 \pm 8.68$ & $12.31 \pm 7.98$ & $<0.0001$ \\
\hline 0 & $60,885(11.00)$ & $60,694(11.00)$ & $191(12.49)$ & $<0.0001$ \\
\hline \multicolumn{5}{|l|}{ Benign breast disease, No $\left(\%^{\dagger}\right)$} \\
\hline No & $379,377(68.55)$ & $378,388(68.56)$ & $989(64.68)$ & 0.0011 \\
\hline Yes & 174,057 (31.45) & $173,517(31.44)$ & $540(35.32)$ & \\
\hline \multicolumn{5}{|c|}{ Surgeries on the reproductive system, No $\left(\%^{\dagger}\right)$} \\
\hline No & $474,009(85.65)$ & $472,716(85.65)$ & $1,293(84.57)$ & 0.2262 \\
\hline Yes & $79,425(14.35)$ & $79,189(14.35)$ & $236(15.43)$ & \\
\hline \multicolumn{5}{|l|}{ Histology type ${ }^{\S}$} \\
\hline Adenocarcinoma & NA & NA & $1,202(91.20)$ & NA \\
\hline
\end{tabular}

${ }^{\dagger}$, column percentage; ${ }^{\ddagger}$, among postmenopausal women only; ${ }^{\S}, 211$ lung cancer cases without information on histological type. SD, standard derivation; BMI, body-mass index.

age (25-29, or $\geq 30$ years) at first live birth (vs. $<25$ year: $\mathrm{HR}=1.31,95 \%$ CI: $1.17-1.47$; HR $=1.31,95 \%$ CI: $1.07-1.60$ ), benign breast disease history ( $\mathrm{HR}=1.27,95 \%$ CI: $1.13-1.44)$ and reproductive system surgical history (HR $=1.15$; 95\% CI: 1.00-1.33). Decreased lung cancer risk was associated with a longer time ( $\geq 13$ months) of breastfeeding ( $v s$. no breastfeeding: HR $=0.82$; $95 \%$ CI: 0.69-0.98). Among postmenopausal females, those who experienced surgical menopause were at increased lung cancer risk ( $\mathrm{HR}=1.64 ; 95 \% \mathrm{CI}$ : 1.31-2.06). As for adenocarcinoma specifically, similar risk estimates were noted compared with overall lung cancer risk. Additionally, normal (45-49, or 50-54) age at menopause was associated with decreased lung adenocarcinoma risk (vs. $<45$ years: $\mathrm{HR}=1.64$; 95\% CI: $1.31-2.06$ ). The association concerning surgery on the reproductive system converted to be insignificant.

Figure 2 presented the dose-response associations between reproductive factors and lung cancer risk. Significant nonlinear association was only suggested concerning the age at menopause ( $\mathrm{P}$-overall $=0.0160$, $\mathrm{P}$-nonlinear $=0.0126)$. Lung cancer risks increased with age at menopause above 50 or below 45 , somehow the association was insignificant concerning menopause age younger than 45. Age at menarche (P-overall $<0.0001, \mathrm{P}$-nonlinear $=0.6486)$, time of breastfeeding 
Table 2 Risk of developing lung cancer in relationship to baseline menstrual and reproductive factors

\begin{tabular}{|c|c|c|c|c|}
\hline \multirow{2}{*}{ Factors } & \multicolumn{2}{|c|}{ Lung cancer } & \multicolumn{2}{|c|}{ Adenocarcinoma } \\
\hline & Cases $(\mathrm{N}=1,529)$ & $\mathrm{HR}^{\dagger}(95 \% \mathrm{Cl})$ & Cases $(\mathrm{N}=1,202)$ & $\mathrm{HR}^{\dagger}(95 \% \mathrm{Cl})$ \\
\hline \multicolumn{5}{|l|}{ Age at menarche, year } \\
\hline$<13$ & 137 & Ref & 107 & Ref \\
\hline 13 & 269 & $1.12(0.91-1.37)$ & 207 & $1.11(0.88-1.40)$ \\
\hline$\geq 16$ & 449 & $1.43(1.17-1.73)$ & 359 & $1.49(1.20-1.86)$ \\
\hline \multicolumn{5}{|l|}{ Menopause status $^{\ddagger}$} \\
\hline Natural menopause & 1,200 & Ref & 921 & Ref \\
\hline Surgical menopause & 81 & $1.64(1.31-2.06)$ & 72 & $1.85(1.45-2.35)$ \\
\hline $45-49$ & 385 & $0.78(0.61-1.00)$ & 301 & $0.71(0.55-0.93)$ \\
\hline $50-54$ & 737 & $0.86(0.68-1.08)$ & 561 & $0.76(0.59-0.98)$ \\
\hline$\geq 55$ & 81 & $0.95(0.69-1.29)$ & 63 & $0.86(0.61-1.22)$ \\
\hline \multicolumn{5}{|c|}{ Reproductive period ${ }^{\ddagger}$, year } \\
\hline$<30$ & 92 & Ref & 79 & Ref \\
\hline $30-34$ & 402 & $0.83(0.67-1.05)$ & 308 & $0.85(0.67-1.06)$ \\
\hline $35-39$ & 690 & $0.80(0.65-1.00)$ & 536 & $0.83(0.67-1.03)$ \\
\hline$\geq 40$ & 97 & $0.80(0.60-1.16)$ & 70 & $0.84(0.63-1.12)$ \\
\hline \multicolumn{5}{|c|}{ Duration of breastfeeding, month } \\
\hline 0 & 191 & Ref & 154 & Ref \\
\hline $1-12$ & 963 & $0.99(0.84-1.15)$ & 765 & $0.99(0.83-1.18)$ \\
\hline$\geq 13$ & 375 & $0.82(0.69-0.98)$ & 283 & $0.81(0.66-0.99)$ \\
\hline \multicolumn{5}{|l|}{ Benign breast disease } \\
\hline No & 989 & Ref & 759 & Ref \\
\hline Yes & 540 & $1.27(1.13-1.44)$ & 443 & $1.33(1.16-1.52)$ \\
\hline \multicolumn{5}{|c|}{ Surgery on the reproductive system } \\
\hline No & 1,293 & Ref & 1,012 & Ref \\
\hline Yes & 236 & $1.15(1.00-1.33)$ & 190 & $1.15(0.98-1.35)$ \\
\hline
\end{tabular}

${ }^{\dagger}$, adjusted for age at enrollment (continuous), education (low, medium, or high), BMI (underweight, normal, overweight or obese), smoking status (current, former or never-smoker), exposures to environmental tobacco smoke (yes or no), exposure to cooking smoke (none, little, some, or much), occupational exposures (yes or no), history of chronic respiratory disease (yes or no) and family history of lung cancer (yes or no). Province of different economic region was treated as a random variable considering within-cluster correlation. ${ }^{\ddagger}$, among postmenopausal women only. $\mathrm{HR}$, hazard ratio; $\mathrm{Cl}$, confidence interval. 
A

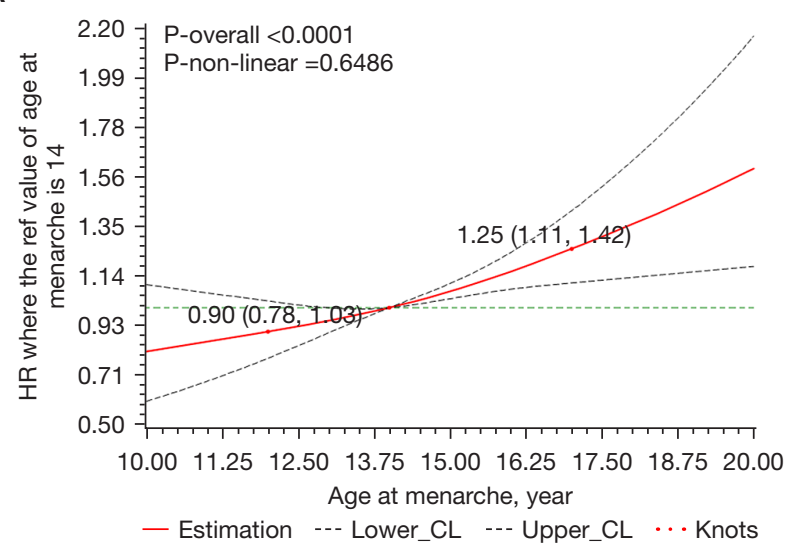

C

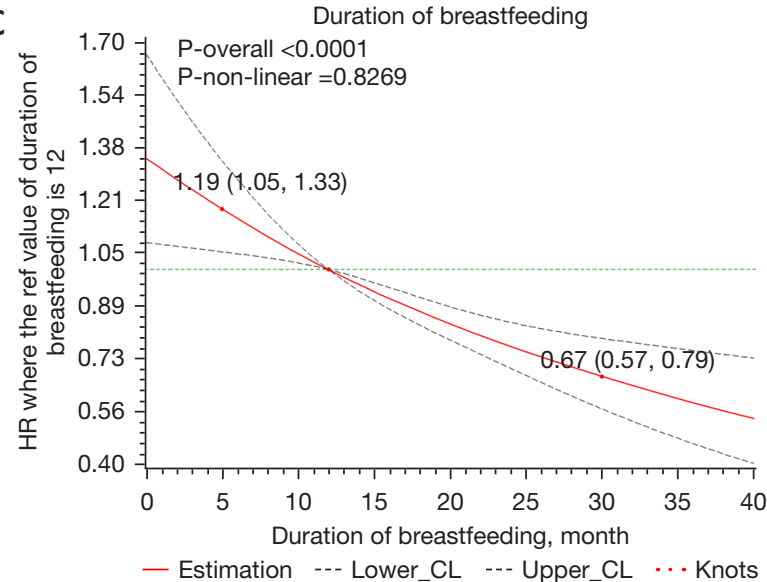

$E$

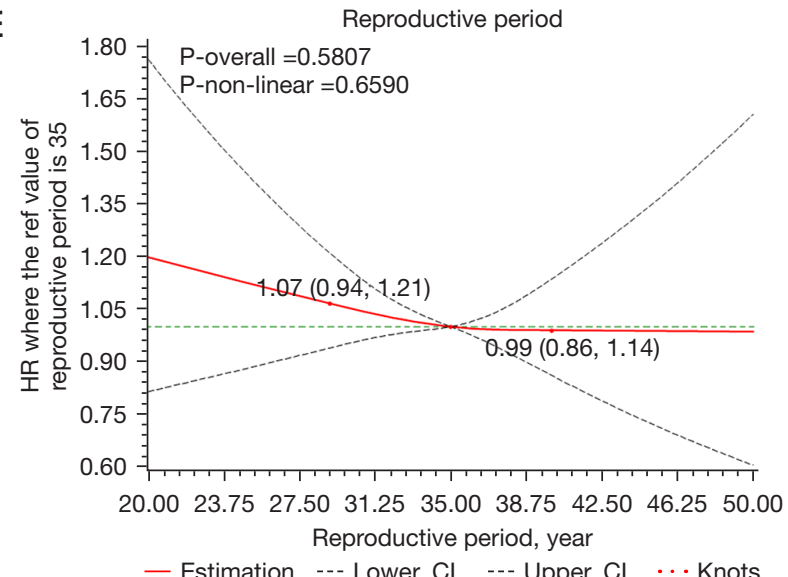

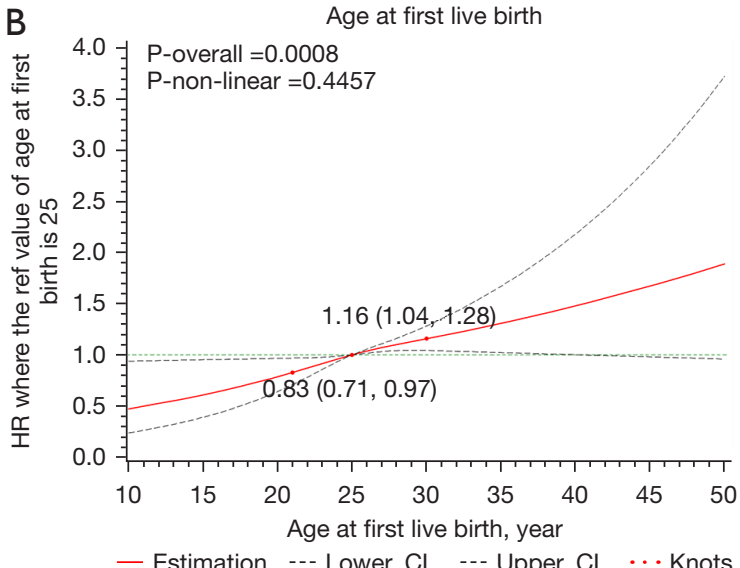

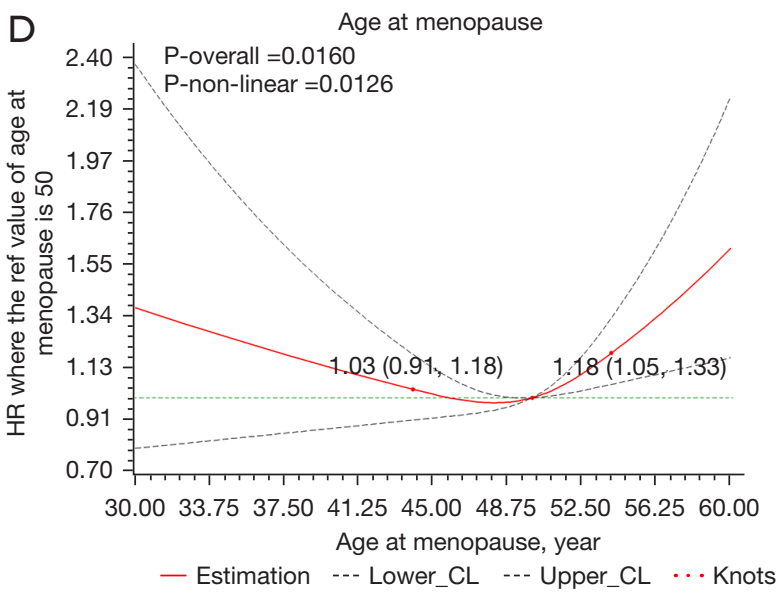

Figure 2 Cubic spline graph of the adjusted HR (represented by solid line) and $95 \% \mathrm{CI}$ (represented by the dotted lines) for the association between menstrual and reproductive factors and lung cancer risk. (A) Age at menarche, reference: 14 years old; (B) age at first live birth, reference: 25 years old; (C) duration of breastfeeding, reference: 12 months; (D) age at menopause, reference: 50 years old; (E) reproductive period, reference: 35 years; Knots: 5th, 50th, 95th of the distribution. Analyses are adjusted for age at enrollment (continuous), education (low, medium, or high), BMI (underweight, normal, overweight or obese), smoking status (current, former or never-smoker), exposures to environmental tobacco smoke (yes or no), exposure to cooking smoke (none, little, some, or much), occupational exposures (yes or no), history of chronic respiratory disease (yes or no) and family history of lung cancer (yes or no). 
$(\mathrm{P}$-overall $=0.0008, \mathrm{P}$-nonlinear $=0.4457)$ and duration of breastfeeding $(\mathrm{P}$-overall $<0.0001, \mathrm{P}$-nonlinear $=0.8269)$ were all approximately linearly associated with lung cancer risk. No significant association was suggested between the reproductive period and lung cancer risk (P-overall $=0.5807)$. For lung adenocarcinoma, similar associations were also noted and displayed in Figure S1.

Adjusted for multiple covariates and all significant reproductive factors in Table 2, lung cancer and adenocarcinomaspecific risk among all recruited females and postmenopausal females only were further estimated in multivariable models (Table 3). Despite of insignificant association concerning time of breastfeeding ( $\geq 13$ months $v$ s. no breastfeeding: $\mathrm{HR}=0.86$; 95\% CI: 0.71-1.04), significant risk increases were confirmed among females with later age $(15$, or $\geq 16$ years) at menarche (vs. $<13$ years: $\mathrm{HR}=1.27,95 \% \mathrm{CI}$ : 1.04-1.56; HR $=1.45$, 95\% CI: 1.19-1.76), later age (25-29, or $\geq 30$ years $)$ at first live birth ( $<25$ years: $H R=1.27,95 \%$ CI: $1.13-1.43$; HR $=1.23$, 95\% CI: $1.00-1.51)$, and benign breast disease history ( $\mathrm{HR}=1.25,95 \% \mathrm{CI}: 1.10-1.41$ ). No additional association was suggested for adenocarcinoma. Specific to postmenopausal females, those who experienced surgical menopause (HR $=1.62 ; 95 \% \mathrm{CI}: 1.29-2.05)$ and other surgeries on the reproductive system $(\mathrm{HR}=1.19$; 95\% CI: 1.01-1.40) were at significantly increased lung cancer risks. Similar risk estimates were noted for lung adenocarcinoma risk among postmenopausal females.

Sensitivity analyses among lifetime never smokers were displayed in Table 4. Among nonsmoking females, a longer duration of breastfeeding ( $\geq 13$ months) was significantly associated with decreased overall lung cancer risk ( $v s$. no breastfeeding: $\mathrm{HR}=0.82 ; 95 \% \mathrm{CI}: 0.67-1.00)$, and especially adenocarcinoma risk (HR $=0.65 ; 95 \%$ CI: $0.53-0.81)$.

\section{Discussion}

Based on a large-scale multi-centered cohort study of Chinese females, this analysis displayed elevated lung cancer risk among females with later age (15, or $\geq 16$ years) at menarche, later age (25-29, or $\geq 30$ years) at first live birth, and benign breast disease history. For postmenopausal females specifically, surgical menopause and surgical history of the reproductive system other than hysterectomy and oophorectomy both appeared to be predictive of elevated lung cancer risk. A nonlinear association was observed concerning the age at menopause, suggesting increased lung cancer risks with age at menopause below 45 and especially, above 50. Although we observed no significant associations between longer time ( $\geq 13$ months) of breastfeeding and lung cancer risk among all participants, significantly decreased adenocarcinoma risk was noted among nonsmoking females.

So far, 11 cohort studies were performed on the association between hormonal factors and lung cancer risk and yielded inconsistent results (Table S1). Notably, our study firstly addressed the associations among Chinese females with the estimation of adenocarcinoma-specific lung cancer risk based on a large-scale multi-center cohort. It is noteworthy that the restricted cubic spline analysis was also firstly applied to evaluate the nonlinear association between continuous menstrual factors and lung cancer risk.

In this analysis, we observed that later age at menarche was associated with increased lung cancer risk. Although this may suggest that the role of hormonal factors in adolescence as initiating factors for subsequent lung pathologies, it should be noted that age at menarche can be influenced by many exposures in early life which were unable to be measured in our study. Our finding corroborates the published meta-analysis (34) and especially several Chinese studies $(21-23,25,26)$. In contrast to our findings, some studies reported a reduced lung cancer risk associated with late menarche $(16,19)$, however, subsequent results based on the same cohort were paradoxical (18). There were also two Chinese studies $(32,33)$ that suggested inverse associations, which provide insufficient evidence based on the case-control study design.

Consistent with several studies $(17,36)$, we noted a similar positive association with age at first live birth. Since the self-regulating capacity in endogenous estrogen decreases as females get older, late childbirth may be more likely to cause hormonal disorders. Nonetheless, other studies also reported either non-significant $(15,19,23,24,26,31)$ or reduced risks $(16,30,33)$. In these studies, the categories of age at first live birth were not unified in these analyses, which might limit the comparability of these findings. Besides, a few studies have suggested decreased risks for higher parity $(22,26)$, however, the influence of parity was not evaluated in our analysis.

We observed that benign breast disease history was positively associated with lung cancer risk. However, there was no evidence before reporting the relationship of benign breast disease to lung cancer risk. Though we considered benign breast disease as an indicator of hormonal disturbances and elevated lung cancer risk, this innovative association was plausive considering the detection signal bias. Therefore, more evidence is needed concerning this assertion. 
Table 3 Multivariable model for lung cancer risk

\begin{tabular}{|c|c|c|c|c|c|c|c|c|}
\hline \multirow{2}{*}{ Factors } & \multicolumn{4}{|c|}{ All females recruited } & \multicolumn{4}{|c|}{ Postmenopausal females } \\
\hline & $\begin{array}{c}\text { Cases } \\
(\mathrm{N}=1,529)\end{array}$ & $\begin{array}{c}\text { Model } a^{\dagger} \\
\text { HR }(95 \% \mathrm{Cl})\end{array}$ & $\begin{array}{c}\text { Cases } \\
(\mathrm{N}=1,202)\end{array}$ & $\begin{array}{c}\text { Model } a^{\dagger} \\
\text { HR }(95 \% \mathrm{Cl})\end{array}$ & $\begin{array}{c}\text { Cases } \\
(\mathrm{N}=1,281)\end{array}$ & $\begin{array}{c}\text { Model b } \\
\text { HR }(95 \% \text { Cl) }\end{array}$ & $\begin{array}{c}\text { Cases } \\
(\mathrm{N}=993)\end{array}$ & $\begin{array}{c}\text { Model b } \\
\text { HR }(95 \% \text { Cl) }\end{array}$ \\
\hline \multicolumn{9}{|c|}{ Menopause status } \\
\hline \multicolumn{9}{|c|}{ Age at menopause, year } \\
\hline$<45$ & & & & & 78 & Ref & 68 & Ref \\
\hline $45-49$ & & & & & 385 & $0.86(0.67-1.10)$ & 301 & $0.80(0.61-1.05)$ \\
\hline \multicolumn{9}{|c|}{ Age at menarche, year } \\
\hline$<13$ & 137 & Ref & 107 & Ref & 100 & Ref & 77 & Ref \\
\hline 13 & 269 & $1.14(0.92-1.40)$ & 207 & $1.07(0.84-1.36)$ & 224 & $1.25(0.98-1.58)$ & 171 & $1.25(0.96-1.64)$ \\
\hline 14 & 363 & $1.15(0.94-1.40)$ & 275 & $1.09(0.87-1.37)$ & 298 & $1.22(0.97-1.53)$ & 219 & $1.19(0.91-1.54)$ \\
\hline 15 & 311 & $1.27(1.04-1.56)$ & 254 & $1.29(1.02-1.63)$ & 260 & $1.33(1.05-1.68)$ & 211 & $1.43(1.10-1.86)$ \\
\hline$\geq 16$ & 449 & $1.45(1.19-1.76)$ & 359 & $1.48(1.19-1.86)$ & 399 & $1.51(1.21-1.89)$ & 315 & $1.58(1.23-2.03)$ \\
\hline \multicolumn{9}{|c|}{ Age at first live birth, year } \\
\hline Nulliparous & 31 & $1.20(0.81-1.78)$ & 23 & $1.08(0.67-1.76)$ & 24 & $1.29(0.83-2.02)$ & 19 & $1.36(0.82-2.24)$ \\
\hline $1-12$ & 963 & $1.02(0.80-1.13)$ & 765 & $0.99(0.82-1.21)$ & 792 & $1.04(0.86-1.25)$ & 618 & $1.03(0.83-1.27)$ \\
\hline$\geq 13$ & 375 & $0.86(0.71-1.04)$ & 283 & $0.82(0.66-1.03)$ & 334 & $0.87(0.70-1.07)$ & 249 & $0.85(0.67-1.08)$ \\
\hline \multicolumn{9}{|c|}{ Benign breast disease } \\
\hline No & 989 & Ref & 759 & Ref & 864 & Ref & 653 & Ref \\
\hline Yes & 540 & $1.25(1.10-1.41)$ & 443 & $1.29(1.12-1.49)$ & 417 & $1.16(1.01-1.33)$ & 340 & $1.21(1.04-1.40)$ \\
\hline \multicolumn{9}{|c|}{ Surgery on the reproductive system } \\
\hline No & 1,293 & Ref & 1012 & Ref & 1,094 & Ref & 844 & Ref \\
\hline Yes & 236 & $1.10(0.96-1.28)$ & 190 & $1.08(0.91-1.28)$ & 187 & $1.19(1.01-1.40)$ & 149 & $1.20(1.00-1.44)$ \\
\hline
\end{tabular}

${ }^{\dagger}$, model a includes age at menarche, age at first live birth, duration of breastfeeding, benign breast disease, surgery of the reproductive system, age at enrollment (continuous), education (low, medium, or high), BMI (underweight, normal, overweight or obese), smoking status (current, former or never-smoker), exposures to environmental tobacco smoke (yes or no), exposure to cooking smoke (none, little, some, or much), occupational exposures (yes or no), history of chronic respiratory disease (yes or no) and family history of lung cancer (yes or no). Province of different economic region was treated as a random variable considering within-cluster correlation. ${ }^{\ddagger}$, model $\mathrm{b}$ further includes menopause status and age at menopause based on Model a. HR, hazard ratio; $\mathrm{Cl}$, confidence interval. 
Table 4 Multivariable model for lung cancer risk among lifetime never-smokers

\begin{tabular}{|c|c|c|c|c|c|c|c|c|}
\hline \multirow{3}{*}{ Factors } & \multicolumn{4}{|c|}{ All females recruited } & \multicolumn{4}{|c|}{ Postmenopausal females } \\
\hline & \multicolumn{2}{|c|}{ Lung cancer } & \multicolumn{2}{|c|}{ Adenocarcinoma } & \multicolumn{2}{|c|}{ Lung cancer } & \multicolumn{2}{|c|}{ Adenocarcinoma } \\
\hline & $\begin{array}{c}\text { Cases } \\
(\mathrm{N}=1,454)\end{array}$ & $\begin{array}{l}\text { Model } \mathrm{a}^{\dagger}, \mathrm{HR} \\
\quad(95 \% \mathrm{Cl})\end{array}$ & $\begin{array}{c}\text { Cases } \\
(\mathrm{N}=1,143)\end{array}$ & $\begin{array}{l}\text { Model } \mathrm{a}^{\dagger}, \mathrm{HR} \\
\quad(95 \% \mathrm{Cl})\end{array}$ & $\begin{array}{c}\text { Cases } \\
(\mathrm{N}=1,220)\end{array}$ & $\begin{array}{c}\text { Model } b^{\ddagger}, \text { HR } \\
(95 \% \mathrm{Cl})\end{array}$ & $\begin{array}{c}\text { Cases } \\
(\mathrm{N}=946)\end{array}$ & $\begin{array}{l}\text { Model } b^{\ddagger}, \text { HR } \\
\quad(95 \% \text { Cl })\end{array}$ \\
\hline \multicolumn{9}{|c|}{ Menopause status } \\
\hline \multicolumn{9}{|c|}{ Age at menopause, year } \\
\hline$<45$ & & & & & 75 & Ref & 65 & Ref \\
\hline $45-49$ & & & & & 364 & $0.84(0.65-1.09)$ & 282 & $0.78(0.59-1.03)$ \\
\hline$<13$ & 129 & Ref & 103 & Ref & 95 & Ref & 75 & Ref \\
\hline 13 & 250 & $1.11(0.90-1.37)$ & 191 & $1.16(0.92-1.47)$ & 208 & $1.21(0.95-1.54)$ & 158 & $1.17(0.89-1.55)$ \\
\hline 14 & 345 & $1.15(0.93-1.40)$ & 259 & $1.17(0.94-1.47)$ & 284 & $1.21(0.96-1.53)$ & 206 & $1.13(0.86-1.47)$ \\
\hline 15 & 292 & $1.24(1.01-1.53)$ & 240 & $1.42(1.13-1.78)$ & 242 & $1.27(1.00-1.62)$ & 198 & $1.34(1.02-1.75)$ \\
\hline$\geq 16$ & 438 & $1.46(1.19-1.78)$ & 350 & $1.58(1.27-1.97)$ & 391 & $1.52(1.21-1.90)$ & 309 & $1.54(1.19-1.98)$ \\
\hline \multicolumn{9}{|c|}{ Age at first live birth, year } \\
\hline Nulliparous & 26 & $1.07(0.69-1.64)$ & 20 & $1.09(0.69-1.73)$ & 20 & $1.16(0.71-1.88)$ & 16 & $1.24(0.72-2.12)$ \\
\hline $1-12$ & 925 & $0.99(0.83-1.18)$ & 733 & $0.94(0.78-1.14)$ & 765 & $1.03(0.85-1.25)$ & 596 & $1.03(0.83-1.28)$ \\
\hline$\geq 13$ & 353 & $0.82(0.67-1.00)$ & 268 & $0.65(0.53-0.81)$ & 314 & $0.84(0.68-1.05)$ & 236 & $0.84(0.66-1.08)$ \\
\hline \multicolumn{9}{|c|}{ Benign breast disease } \\
\hline No & 960 & Ref & 738 & Ref & 838 & Ref & 635 & Ref \\
\hline Yes & 494 & $1.24(1.10-1.41)$ & 405 & $1.30(1.13-1.49)$ & 382 & $1.15(1.01-1.33)$ & 311 & $1.21(1.03-1.41)$ \\
\hline \multicolumn{9}{|c|}{ Surgery on the reproductive system } \\
\hline No & 1,236 & Ref & 968 & Ref & 1,050 & Ref & 811 & Ref \\
\hline Yes & 218 & $1.10(0.94-1.27)$ & 175 & $1.11(0.95-1.31)$ & 170 & $1.16(0.98-1.37)$ & 135 & $1.16(0.96-1.41)$ \\
\hline
\end{tabular}

$\mathrm{HR}$, hazard ratio; $\mathrm{Cl}$, confidence interval. $\dagger$, Model a adjusted for age at menarche, age at first live birth, duration of breastfeeding, benign breast disease, surgery of the reproductive system, age at enrollment (continuous), education (low, medium, or high), BMl (underweight, normal, overweight or obese), smoking status (current, former or never-smoker), exposures to environmental tobacco smoke (yes or no), exposure to cooking smoke (none, little, some, or much), occupational exposures (yes or no), history of chronic respiratory disease (yes or no) and family history of lung cancer (yes or no). Province of different economic region was treated as a random variable considering within-cluster correlation. $\ddagger$, Model $b$ adds menopause status and age at menopause to Model a. 
For postmenopausal females, our findings are consistent with several previous studies that have noted elevated risks of lung cancer associated with surgical menopause $(15,16,26)$. Many studies $(17,18,20,25,33,36)$, although not all $(19,21,22,24,31,37)$ have found positive associations with age at menopause. In our analysis, we initially observed no relationship of age at menopause to lung cancer risk. However, significant non-linear associations appeared in the cubic spline graph, which suggests that late ( $>50$ years) menopause especially elevated the risk of lung cancer. Since the HRs below 45 also revealed increased lung cancer risk despite of the insignificant intervals, we considered that there may be a normal range (in a medical sense) for menopause age concerning the health status and lower lung cancer risk. Notably, some studies reported inverse associations between age at menopause and lung cancer risk $(15,23,30,32,38)$, which are opposite to our findings. These opposite results were mainly attributed to different ethnicity. The recent meta-analysis (34) suggested that hormonal effects varied by population and race. For Western females, older age at menopause was significantly associated with decreased lung cancer risk, whereas more evidence was required for Asian females. We observed no association between lung cancer risk and the reproductive period, in agreement with most investigations $(23,39)$, but in contrast with several studies that have noted either reduced (23) or increased (18) risks.

Consistent with an investigation that observed an inverse association concerning the time of breastfeeding to lung cancer risk (18), we noted a similar association for especially adenocarcinoma risk. Initially, we also observed an inverse association between the duration of breastfeeding and lung cancer risk. However, this association was not particularly convincing after adjustment for multiple covariates and other factors. Though breastfeeding was proved to be protective for females from breast and ovarian cancer (40), the role of breastfeeding in lung carcinogenesis still needs further clarity.

As sex-specific factors, estrogens are postulated as important agents in female cancer development and progression $(14,41)$, which exhibits various physiological functions including regulation of the menstrual cycle and reproduction (42). Potential hormonal involvement in the etiology of lung cancer has been supported by a fair amount of experimental evidence, including abundant expression of estrogen receptors, progesterone receptors, and human epidermal growth factor receptors in both normal and tumor lung tissues (10-12). However, the potential biological mechanisms on this effect concerning lung cancer risk are still not clear. There is a speculation that the association between hormonal factors and lung cancer risk may be attributed to the cell proliferative properties of estrogen (43). However, this may be just an assumption and requires further evidence.

Our study had several strengths over previous studies. In contrast to the case-control designs, this prospective study allowed for extensive information collection at baseline with a large sample size. Confounding risk factors including smoking, exposures to environmental tobacco smoke and cooking fumes were all considered in our study. However, there were also some limitations. First, although we had relatively complete information on the most common risk factors, we were lacking data on exogenous hormonal factors, including the use of oral contraceptives, estrogen, and progestin, and hormone replacement therapy. Most previous studies $(15,16,20,21,23,29,36,44,45)$ to date have claimed no significant association between exogenous hormonal factors and lung cancer risk. Therefore, this study only focused on endogenous hormonal factors. Detailed information on exogenous hormonal factors was also collected with a renewed questionnaire in 2019. In the next step, we plan to make further sufficient explorations of hormonal factors. Second, although our study may suggest that the role of hormonal factors in early life, those exposures that have close ties with hormonal factors, such as BMI and diet in adolescence, were unable to be measured in our study. Birth cohorts with long-term followup and monitoring are further required. Third, the data of exposure variables were collected based on a self-report questionnaire, which may be subject to misclassification and recall bias. Forth, the median follow-up time of this study was relatively short at 3.61 years. The number of identified new lung cancer cases was limited. Evaluations of weaker associations were precluded due to low case numbers, and analyses by subgroups were also restricted. In the context of this study, we will continue to follow up this cohort and make further sufficient explorations. Fifth, since the proportion of ever-smokers was extremely low in our study, we were unable to explain the association in current and former smokers. Therefore, we additionally performed sensitivity analysis in lifetime non-smoking females.

In conclusion, this study finds some support for the role of menstrual and reproductive factors in lung carcinogenesis. Later age at menarche, age at first live birth, age at menopause, and benign breast disease appeared to be predictive of elevated lung cancer risks. Duration 
of breastfeeding was specifically associated with reduced adenocarcinoma risk. However, these relationships were somewhat complex, and required cautious interpretation. Therefore, further investigations addressing the biological mechanisms are needed. Additional studies on cellular changes in the lung tissue may help us further understand the role of hormonal risk factors in the etiology of lung cancer.

\section{Acknowledgments}

The authors sincerely thank all the participants and external expert panels in this study.

Funding: This work was supported by the Ministry of Finance and National Health Commission of the People's Republic of China, National Key Research \& Development Program of China (Grant number: 2018YFC1315000/2018YFC1315001), Non-profit Central Research Institute Fund of Chinese Academy of Medical Sciences (Grant number: 2019PT320027 and 2020PT330001), CAMS Innovation Fund for Medical Science (Grant number: 2019-I2M-2-002), Sanming Project of Medicine in Shenzhen (Grant number: SZSM201911015), National Natural Science Foundation of China (8187102812), and the Beijing Science and Technology Project (Grant number: Z181100001718212).

\section{Footnote}

Reporting Checklist: The authors have completed the STROBE reporting checklist. Available at https://dx.doi. org/10.21037/tlcr-21-552

Data Sharing Statement: Available at https://dx.doi. org/10.21037/tlcr-21-552

Conflicts of Interest: All authors have completed the ICMJE uniform disclosure form (available at https://dx.doi. org/10.21037/tlcr-21-552). The authors have no conflicts of interest to declare.

Ethical Statement: The authors are accountable for all aspects of the work in ensuring that questions related to the accuracy or integrity of any part of the work are appropriately investigated and resolved. The study was conducted in accordance with the Declaration of Helsinki and approved by the Ethics Committee of China National Cancer Center/Cancer Hospital, Chinese Academy of
Medical Sciences and Peking Union Medical College (number of IRB:15-070/997). Informed consent was taken from all individual participants.

Open Access Statement: This is an Open Access article distributed in accordance with the Creative Commons Attribution-NonCommercial-NoDerivs 4.0 International License (CC BY-NC-ND 4.0), which permits the noncommercial replication and distribution of the article with the strict proviso that no changes or edits are made and the original work is properly cited (including links to both the formal publication through the relevant DOI and the license). See: https://creativecommons.org/licenses/by-nc-nd/4.0/.

\section{References}

1. Sung H, Ferlay J, Siegel RL, et al. Global Cancer Statistics 2020: GLOBOCAN Estimates of Incidence and Mortality Worldwide for 36 Cancers in 185 Countries. CA Cancer J Clin 2021;71:209-49.

2. Zhang S, Sun K, Zheng R, et al. Cancer incidence and mortality in China, 2015. Journal of the National Cancer Center 2021;1:2-11.

3. Zhang SW, Zheng RS, Yang ZX, et al. Trend analysis on incidence and age at diagnosis for lung cancer in cancer registration areas of China, 2000-2014. Zhonghua Yu Fang Yi Xue Za Zhi 2018;52:579-85.

4. Bray F, Ferlay J, Soerjomataram I, et al. Global cancer statistics 2018: GLOBOCAN estimates of incidence and mortality worldwide for 36 cancers in 185 countries. CA Cancer J Clin 2018;68:394-424.

5. Wang JB, Fan YG, Jiang Y, et al. Attributable causes of lung cancer incidence and mortality in China. Thorac Cancer 2011;2:156-63.

6. Shi JF, Wang L, Wu N, et al. Clinical characteristics and medical service utilization of lung cancer in China, 2005-2014: Overall design and results from a multicenter retrospective epidemiologic survey. Lung Cancer 2019;128:91-100.

7. Zeng Q, Vogtmann E, Jia MM, et al. Tobacco smoking and trends in histological subtypes of female lung cancer at the Cancer Hospital of the Chinese Academy of Medical Sciences over 13 years. Thorac Cancer 2019;10:1717-24.

8. Zhou F, Zhou C. Lung cancer in never smokers-the East Asian experience. Transl Lung Cancer Res 2018;7:450-63.

9. Sathish V, Martin YN, Prakash YS. Sex steroid signaling: implications for lung diseases. Pharmacol Ther 2015;150:94-108. 
10. Stabile LP, Davis AL, Gubish CT, et al. Human nonsmall cell lung tumors and cells derived from normal lung express both estrogen receptor alpha and beta and show biological responses to estrogen. Cancer Res 2002;62:2141-50.

11. Raso MG, Behrens C, Herynk MH, et al. Immunohistochemical expression of estrogen and progesterone receptors identifies a subset of NSCLCs and correlates with EGFR mutation. Clin Cancer Res 2009; 15:5359-68.

12. Cheng TD, Darke AK, Redman MW, et al. Smoking, Sex, and Non-Small Cell Lung Cancer: Steroid Hormone Receptors in Tumor Tissue (S0424). J Natl Cancer Inst 2018;110:734-42.

13. Hsu LH, Chu NM, Kao SH. Estrogen, Estrogen Receptor and Lung Cancer. Int J Mol Sci 2017;18:1713.

14. Liang J, Shang Y. Estrogen and cancer. Annu Rev Physiol 2013;75:225-40.

15. Schwartz AG, Ray RM, Cote ML, et al. Hormone Use, Reproductive History, and Risk of Lung Cancer: The Women's Health Initiative Studies. J Thorac Oncol 2015;10:1004-13.

16. Brinton LA, Gierach GL, Andaya A, et al. Reproductive and hormonal factors and lung cancer risk in the NIHAARP Diet and Health Study cohort. Cancer Epidemiol Biomarkers Prev 2011;20:900-11.

17. Baik CS, Strauss GM, Speizer FE, et al. Reproductive factors, hormone use, and risk for lung cancer in postmenopausal women, the Nurses' Health Study. Cancer Epidemiol Biomarkers Prev 2010;19:2525-33.

18. Wilunda C, Sawada N, Yamaji T, et al. Reproductive Factors and Lung Cancer Risk among Never-Smoking Japanese Women with 21 Years of Follow-Up: A Cohort Study. Cancer Epidemiol Biomarkers Prev 2021;30:1185-92.

19. Liu $Y$, Inoue $M$, Sobue T, et al. Reproductive factors, hormone use and the risk of lung cancer among middle-aged never-smoking Japanese women: a large-scale populationbased cohort study. Int J Cancer 2005;117:662-6.

20. Jeon KH, Shin DW, Han K, et al. Female reproductive factors and the risk of lung cancer in postmenopausal women: a nationwide cohort study. Br J Cancer 2020;122:1417-24.

21. Tan HS, Tan MH, Chow KY, et al. Reproductive factors and lung cancer risk among women in the Singapore Breast Cancer Screening Project. Lung Cancer 2015;90:499-508.

22. Seow A, Koh WP, Wang R, et al. Reproductive variables, soy intake, and lung cancer risk among nonsmoking women in the Singapore Chinese Health Study. Cancer
Epidemiol Biomarkers Prev 2009;18:821-7.

23. Weiss JM, Lacey JV Jr, Shu XO, et al. Menstrual and reproductive factors in association with lung cancer in female lifetime nonsmokers. Am J Epidemiol 2008;168:1319-25.

24. Seow A, Poh WT, Teh M, et al. Diet, reproductive factors and lung cancer risk among Chinese women in Singapore: evidence for a protective effect of soy in nonsmokers. Int J Cancer 2002;97:365-71.

25. Jin K, Wu M, Zhou JY, et al. Tobacco Smoking Modifies the Association between Hormonal Factors and Lung Cancer Occurrence among Post-Menopausal Chinese Women. Transl Oncol 2019;12:819-27.

26. Gallagher LG, Rosenblatt KA, Ray RM, et al. Reproductive factors and risk of lung cancer in female textile workers in Shanghai, China. Cancer Causes Control 2013;24:1305-14.

27. Yang G, Shu XO, Chow WH, et al. Soy food intake and risk of lung cancer: evidence from the Shanghai Women's Health Study and a meta-analysis. Am J Epidemiol 2012;176:846-55.

28. Koushik A, Parent ME, Siemiatycki J. Characteristics of menstruation and pregnancy and the risk of lung cancer in women. Int J Cancer 2009;125:2428-33.

29. Kabat GC, Miller AB, Rohan TE. Reproductive and hormonal factors and risk of lung cancer in women: a prospective cohort study. Int J Cancer 2007;120:2214-20.

30. Pesatori AC, Carugno M, Consonni D, et al. Reproductive and hormonal factors and the risk of lung cancer: the EAGLE study. Int J Cancer 2013;132:2630-9.

31. Kreuzer M, Gerken M, Heinrich J, et al. Hormonal factors and risk of lung cancer among women? Int J Epidemiol 2003;32:263-71.

32. Brenner AV, Wang Z, Kleinerman RA, et al. Menstrual and reproductive factors and risk of lung cancer among Chinese women, Eastern Gansu Province, 1994-1998. J Epidemiol 2003;13:22-8.

33. He F, Xie JX, Liu CL, et al. The relationship of lung cancer with menstrual and reproductive factors may be influenced by passive smoking, cooking oil fumes, and tea intake: A case-control study in Chinese women. Medicine (Baltimore) 2017;96:e8816.

34. Zeng H, Yang Z, Li J, et al. Associations between female lung cancer risk and sex steroid hormones: a systematic review and meta-analysis of the worldwide epidemiological evidence on endogenous and exogenous sex steroid hormones. BMC Cancer 2021;21:690.

35. Desquilbet L, Mariotti F. Dose-response analyses using 
restricted cubic spline functions in public health research. Stat Med 2010;29:1037-57.

36. Lim WY, Chen Y, Chuah KL, et al. Female reproductive factors, gene polymorphisms in the estrogen metabolism pathway, and risk of lung cancer in Chinese women. Am J Epidemiol 2012;175:492-503.

37. Ben Khedher S, Neri M, Papadopoulos A, et al. Menstrual and reproductive factors and lung cancer risk: A pooled analysis from the international lung cancer consortium. Int J Cancer 2017;141:309-23.

38. Vohra SN, Sapkota A, Lee MT, et al. Reproductive and Hormonal Factors in Relation to Lung Cancer Among Nepali Women. Front Oncol 2019;9:311.

39. Schwartz AG, Wenzlaff AS, Prysak GM, et al. Reproductive factors, hormone use, estrogen receptor expression and risk of non small-cell lung cancer in women. J Clin Oncol 2007;25:5785-92.

Cite this article as: Yang Z, Wang F, Tan F, Cao W, Xu Y, Qin C, Yu Y, Zhao L, Wen Y, Wu Z, Zheng Y, Liu Y, Yu L, Wei D, Dong D, Cao J, Zhang S, Yan S, Wang N, Liao X, Du L, Li J, Li N, Chen W, He J. Menstrual factors, reproductive history, and risk of lung cancer: a multi-center populationbased cohort study in Chinese females. Transl Lung Cancer Res 2021;10(10):3912-3928. doi: 10.21037/tlcr-21-552
40. Victora CG, Bahl R, Barros AJ, et al. Breastfeeding in the 21st century: epidemiology, mechanisms, and lifelong effect. Lancet 2016;387:475-90.

41. Shang Y. Hormones and cancer. Cell Res 2007;17:277-9.

42. Koos RD. Minireview: Putting physiology back into estrogens' mechanism of action. Endocrinology 2011;152:4481-8.

43. Siegfried JM, Stabile LP. Estrongenic steroid hormones in lung cancer. Semin Oncol 2014;41:5-16.

44. Manson JE, Chlebowski RT, Stefanick ML, et al. Menopausal hormone therapy and health outcomes during the intervention and extended poststopping phases of the Women's Health Initiative randomized trials. JAMA 2013;310:1353-68.

45. Subramanian J, Govindan R. Lung cancer in never smokers: a review. J Clin Oncol 2007;25:561-70. 

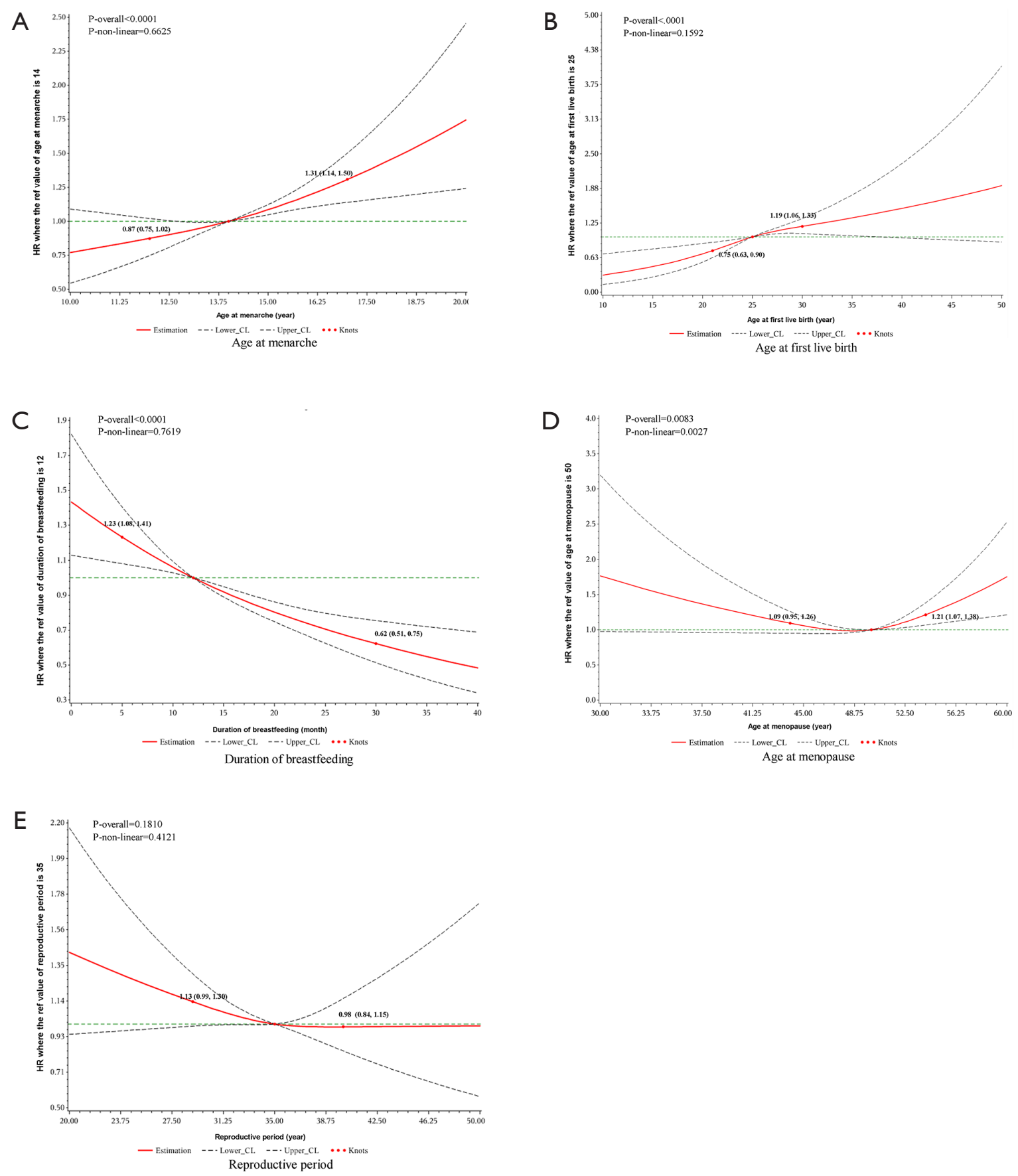

Figure S1 Cubic spline graph of the adjusted HR (represented by solid line) and 95\% CI (represented by the dotted lines) for the association between menstrual and reproductive factors and adenocarcinoma risk. (A) Age at menarche, reference: 14 years old; (B) age at first live birth, reference: 25 years old; (C) duration of breastfeeding, reference: 12 months; (D) Age at menopause, reference: 50 years old; (E) reproductive period, reference: 35 years. Knots: 5th, 50th, 95th of the distribution. Analyses are adjusted for age at enrollment (continuous), education (low, medium, or high), BMI (underweight, normal, overweight or obese), smoking status (current, former or never-smoker), exposures to environmental tobacco smoke (yes or no), exposure to cooking smoke (none, little, some, or much), occupational exposures (yes or no), history of chronic respiratory disease (yes or no) and family history of lung cancer (yes or no). 
Table S1 Characteristics and main findings of existed studies on the associations between menstrual, reproductive factors and lung cancer risk

\begin{tabular}{|c|c|c|c|c|c|c|c|c|c|}
\hline Author & Study name & Country & Premenopausal Status & $\begin{array}{l}\text { Number of } \\
\text { participants }\end{array}$ & $\begin{array}{l}\text { Never- } \\
\text { smokers }\end{array}$ & $\begin{array}{l}\text { Lung cancer } \\
\text { cases }\end{array}$ & Years at enrollment & $\begin{array}{l}\text { Median follow- } \\
\text { up years }\end{array}$ & Main findings \\
\hline Gallagher et al. 2013 & Cohort Study of Shanghai female textile workers & Shanghai, China & Both pre and postmenopausal & 267,400 & N.A. & 824 & 1989-1991 & 9.3 & $\begin{array}{l}\text { Increased lung cancer risk: surgical menopause. } \\
\text { Decreased lung cancer risk: parity. }\end{array}$ \\
\hline Weiss et al. 2008 & Shanghai Women's Health Study & Shanghai, China & Both pre and postmenopausal & 71,314 & 71,314 & 220 & $1996-2000$ & 4.1 & $\begin{array}{l}\text { Decreased lung cancer risk: later age at menopause, longer reproductive period, } \\
\text { higher parity, intrauterine device use. }\end{array}$ \\
\hline Tan et al. 2015 & The Singapore Breast Cancer Screening Project & Singapore & Postmenopausal & 28,222 & 26,473 & 311 & 1994.10-1997.02 & 15.8 & Decreased lung cancer risk: higher parity. \\
\hline Seow et al. 2009 & The Singapore Chinese Health Study & Singapore & Postmenopausal & 35,298 & N.A. & 298 & 1993.04-1998.12 & 9.6 & Decreased lung cancer risk: higher parity. \\
\hline Jeon et al. 2020 & $\begin{array}{l}\text { The Korean National Health Insurance System } \\
\text { based }\end{array}$ & Korea & Postmenopausal & $4,775,398$ & $4,335,259$ & 16,556 & 2009-2014 & 4.4 & Nonsignificant associations. \\
\hline Wilunda et al. 2021 & $\begin{array}{l}\text { The Japan Public Health Center-based } \\
\text { Prospective Study }\end{array}$ & Japan & Both pre and postmenopausal & 42,615 & 42,615 & 400 & 1990-1994 & 21 & $\begin{array}{l}\text { Increased lung cancer risk (adenocarcinoma specific): longer fertility span, late age } \\
\text { at menopause, natural menopause, or surgical menopause. } \\
\text { Decreased lung cancer risk: breastfeeding. }\end{array}$ \\
\hline Lui et al. 2005 & $\begin{array}{l}\text { The Japan Public Health Center-based } \\
\text { Prospective Study }\end{array}$ & Japan & Both pre and postmenopausal & 44,677 & 44,677 & 153 & 1990-1994 & $8-12$ & Increased lung cancer risk: early age at menarche and late age at menopause. \\
\hline Schwartz et al. 2015 & The Women's Health Initiative studies & U.S. & Postmenopausal & 160,855 & 81,031 & 2,467 & 1993.10-1998.12 & 14 & Decreased lung cancer risk: later age at menopause, higher parity. \\
\hline Brinton et al. 2011 & The NIH-AARP Diet and Health Study & U.S. & Postmenopausal & 185,017 & 84,262 & 3,512 & 1995-1996 & 5.7 & $\begin{array}{l}\text { Increased risk: early age at ovarian cessation. } \\
\text { Decreased lung cancer risk: later age at menarche. }\end{array}$ \\
\hline Baik et al. 2010 & The Nurses' Health Study & U.S. & Postmenopausal & 107,171 & 48,227 & 1,729 & 1984 & 22 & $\begin{array}{l}\text { Increased lung cancer risk: earlier age at menopause, exogenous hormone use, } \\
\text { age at first birth (among never smokers). } \\
\text { Decreased lung cancer risk: parity (among never smokers). }\end{array}$ \\
\hline Kabat et al. 2007 & Canadian National Breast Screening Study & Canada & Postmenopausal & 89,812 & 45,065 & 750 & 1980-1985 & 16.4 & $\begin{array}{l}\text { Increased lung cancer risk: higher parity. } \\
\text { Decreased lung cancer risk: later age at first live birth. }\end{array}$ \\
\hline
\end{tabular}

